\title{
Comparative Study of Widal test Against Stool Culture in Diagnosis of Typhoid Fever Suspected Cases in Kano, Northern Nigeria
}

\author{
Abdullahi A. Minjibir ${ }^{1}$, Sani U. Diso ${ }^{1}$, Idris S. Ibrahim ${ }^{1}$, Muhammad S. Abdallah ${ }^{2}$, Muhammad Ali $^{3^{*}}$ \\ ${ }^{\mathrm{T}}$ Department of Pharmaceutical Technology, School of Technology, Kano State Polytechnics, Matan Fada Rd, \\ Nassarawa, Kano, Nigeria \\ ${ }^{2}$ Department of Microbiology, Yobe State University, Nigeria \\ ${ }^{3}$ Department of Microbiology, Federal University Gusau, Zamfara State Nigeria
}

*Corresponding Author

Muhammad Ali

\section{Article History}

Received: 22.09 .2020

Accepted: 03.10.2020

Published: 07.10.2020

\begin{abstract}
The "gold standard" for diagnosis of typhoid fever is the isolation of Salmonella typhi from appropriate samples including blood, stool and urine. The study was aimed to compare Widal test against stool culture for diagnosis of typhoid fever cases in Kano, Northern Nigeria. A completely randomized design is used. A total of 125 subjects (male, $\mathrm{n}=57$ and female, $\mathrm{n}=68$ ) presenting febrile conditions in 4 different health care centers within Kumbotso Local Government Kano State were used for the study. About $5 \mathrm{ml}$ of blood was obtained from each study participant for Widal test and freshly passed faeces were collected for stool culture. The result showed that $22(17.6 \%)$ tested positive for Salmonella typhi by Widal test, whereas $17(13.6 \%)$ tested positive by stool culture. From the result, patients within the age category 21 - 40 years has the highest incidence $9(7.2 \%)$ and $7(5.6 \%)$ for Widal test and stool culture respectively while male has the highest prevalence with 12 and 10 individuals $(9.6 \%$ and $8 \%$ ) while 10 and 7 individual positive samples were female accounted for $8 \%$ and $5.6 \%$ for widal test and stool microcopy respectively. In relation to stool culture, Widal test has high sensitivity $(78.3 \%)$, specificity $(93.6 \%)$, positive predictive value $(68.2 \%)$ and negative predictive value $(98.1 \%)$. There is no significant difference on the prevalence of the infection on the basis of gender, age category and diagnostic methods at $p<0.05$. It is concluded that Widal test can be used as a diagnostic method for detection of Salmonella typhi.
\end{abstract}

Keywords: Typhoid fever, Salmonella, stool culture, Widal test.

\section{INTRODUCTION}

Typhoid fever is a systemic disease caused by Salmonella enterica serotype typhi and is a major cause of morbidity and mortality worldwide [1]. It emerged as an important infectious disease in the early 19th century. Humans are the only natural host and reservoir for typhoid fever agent. Infection occurs in all age groups, and it is transmitted by ingestion of food or water contaminated with feces [2]. The highest incidence occurs where water supplies serving large populations are contaminated with feces [3].

The diagnosis of enteric fever poses several problems due to the non-specific and wide array of clinical features. The common symptoms and signs are fever, vomiting, cough, anorexia, diarrhea, abdominal pain, hepatomegaly, splenomegaly, and coated tongue. Enteric fever should be considered in the differential diagnosis of febrile patients with abdominal symptoms [4]. The common tropical infections such as dengue, enteric fever, leptospirosis, typhus fever, and malaria having similar early presentations can cause confusion in decision-making. Recognition of these diseases is important to diagnose them and treat them early, to avoid potentially fatal complications [5]. Laboratory diagnosis of enteric fever includes Blood culture, Stool Culture and Serological test. Widal test is a common agglutination test employed in the serological diagnosis of enteric fever. This test was developed by Georges Ferdinand Widal in 1896 and helps to detect presence of salmonella antibodies in a patient's serum [6].

Copyright @ 2020: This is an open-access article distributed under the terms of the Creative Commons Attribution license which permits unrestricted use, distribution, and reproduction in any medium for non commercial use (NonCommercial, or CC-BY-NC) provided the original author and source are credited. 
In 1896, Widal developed a procedure for diagnosing typhoid fever based on the fact that antibodies in the blood of an infected individual cause the bacteria to bind together into clumps (the Widal reaction) [7]. The test was based on demonstrating the presence of agglutinin (antibody) in the serum of an infected individual, against the $\mathrm{H}$ (flagellar) and $\mathrm{O}$ (somatic) antigens of Salmonella typhi [8]. The "O" antigen is the somatic antigen of S. typhi and is shared by S. paratyphi A, S. paratyphi B, other Salmonella species and other members of the Enterobacteriaceae family [9]. Antibodies against the $\mathrm{O}$ antigen are predominantly IgM, rise early (appear on day 6 to 8) in the illness and disappear early [9]. The $\mathrm{H}$ antigens are flagellar antigens of $S$. typhi, paratyphi A and paratyphi $\mathrm{B}$. Antibodies to $\mathrm{H}$ antigens are both $\operatorname{IgM}$ and $\operatorname{IgG}$, rise late (on days 10 to 12 ) in the illness and persist for a longer time [9, 10]. Serological diagnosis relies classically on the demonstration of a rising titre of antibodies in paired samples at an interval of 10 to 14 days [11].

In typhoid fever, stool cultures are usually positive from the second week of the infection. Stool is usually plated on agar and also inoculated into fluid enrichment media such as selenite broth. Suspicious colonies from culture plates are tested directly for the presence of salmonella $\mathrm{O}$ antigens by slide agglutination and sub-cultured to peptone water for determination of $\mathrm{H}$ antigen structure and for further biochemical analysis [12]. The objective of this study was to evaluate the performance of Widal test and stool microscopy and to compare the diagnostic accuracy of these tests as tools for diagnosis of enteric fever.

\section{Materials AND Method Study Area}

This research was conducted in Kumbotso Local Government Area of Kano State, Nigeria. The Local Government area was created in 1976 [13]. The Local Government area has eleven (11) wards. It has an area of $158 \mathrm{~km}^{2}$ and total population of two hundred and ninety four thousand, three hundred and ninety one $(294,391)$ residents with population density of $2,197.47$ person/ $\mathrm{km}^{2}$ [13]. According to National population commission, the populations are expected to reach to 374,200 by the year 2011. It is located at an elevation of 450 meters above sea level. Its coordinates on a map are $11^{0} 53^{\prime} \mathrm{N}$ latitudinally and $8^{0} 30^{\prime} \mathrm{E}$ longitudinally [14]. Major towns in the local government are Kumbotso town, Chiranci, Sheka, Dan-bare, Challawa, Panshekara etc. Farming remains a major occupation in the area. However many educated indigenes in the area are employed in the formal sector while others engaged in various trading activities.

\section{Study Population}

A completely randomized design is used. A total of 125 subjects (male, $n=57$ and female, $n=68$ ) presenting febrile conditions suggestive of malaria, dengue virus fever or typhoid fever in 4 different health care centers which are the most populated area in the Local Government (Chiranchi $n=43$, Sheka n= 42, Dan-bare $n=38$ and Panshekara $n=37$ ) within Kumbotso Local Government Kano State were used for the study. It included individuals of all ages and sexes.

\section{Sample Collection}

Specimens were collected from the febrile patient, who presented themselves at the health centers within the study site from a period of April 2015 to October, 2015. Specimens for this study were blood and stool for Widal and stool culture respectively. $5 \mathrm{ml}$ of blood was obtained from each study participant upon routine venepuncture for Widal test. Blood samples in plain tubes were allowed to clot and the clot removed by centrifuge and the supernatant obtained was serum. Freshly passed faeces were collected in a sterile wide mouthed container. Each sample container was labeled with the patient's code number, date and time.

\section{Questionnaire Design, Distribution and Retrieval}

A total of a hundred (125) questionnaires were designed using open ended questions to provide information about the socio-demographic factors of participants and predisposing factors to both infections. Informed consents were obtained from all participants before inclusion. Guardians gave consent for minors.

\section{Widal Agglutination Test for Salmonella Antibodies}

Widal agglutination test was performed on each blood sample using the Widal agglutination kit (Biotech Lab, United States) according to manufacturer's instruction. The reagents contained Salmonella typhi O and $\mathrm{H}$ antigens and Salmonella paratyphi A, B and C antigens. Positive and negative controls were included and a titre greater than or equal to $1 / 80$ indicates salmonella infection. The reagents and samples were brought to room temperature and the antigens were shaken properly to mix well before dispensing. A drop of patient's serum to be tested was placed onto each of the required number of circles on the tile, and then one drop of Widal antigen suspension was added to the reaction circles containing patient serum. Using different mixing applicator sticks provided, the tile was rocked gently back and forth and observed for agglutination macroscopically for one minute.

\section{Stool Culture}

Feces were inoculated onto the surface of Nutrient, MacConkey and Salmonella Shigella Agar (SSA) (Life save Biotech, USA) for isolation, cultivation and differentiation of Salmonella typhi according to method describe by Prescott 
et al., [15]. During the process, a sterile wire loop was deep into the fecal sample of the patients and streaked onto the surface of the agars. The procedure was repeated for all the samples and the plates were incubated $37^{\circ} \mathrm{C}$ for 24 hours. The presumptive colony of Salmonella typhi from each plate was further sub-cultured to obtained pure culture. The pure isolates of Salmonella typhi were preserved in peptone water for further use. The preserved isolates were confirmed as $S$. typhi using conventional microbiological methods which include Gram staining, lactose fermentation and motility test as well as biochemical (Indole, methyl orange, Voges Proskauer, nitrate reduction and citrate utilization) tests according to the methods described by Cheesbrough [16] and Holt et al., [17].

\section{Statistical Analysis}

Statistical analysis package for social sciences (SPSS) version 10.0 was used for statistical analysis of the data generated. Chi square was used to compare between two or more variables. Statistical significance was considered at $\mathrm{p}$ value $<0.05$

\section{Ethical Consideration}

The study was conducted following ethical approval obtained from the Health Services Management Board, Kano State based on the consent of Ethical Committee of Health Department of Kumbotso Local Government Area of Kano State.

\section{RESULTS}

\section{Socio-demographic Factors of the Participants}

A total of $57(46 \%)$ males and $68(54 \%)$ females took part in this study with ages ranging from less than 20 to over 40 years. Majority of the participants were 20 to 40 years age bracket. Participant from rural area accounted for $58 \%$ (72 subjects) while 42\% (53 subjects) are from urban area. Most female participants are house wives males participant are mostly students, civil servant and farmers.

Table-1: Socio-demographic Factors of the Participants with Percentage Frequency

\begin{tabular}{|l|l|l|l|}
\hline Parameter & Male (n) & Female (n) & Total (n) \\
\hline Age $($ Years) & & & \\
\hline $0-20$ & $14(12 \%)$ & $18(14 \%)$ & $32(26 \%)$ \\
\hline $21-40$ & $25(20 \%)$ & $22(17 \%)$ & $47(37 \%)$ \\
\hline $41-60$ & $12(10 \%)$ & $18(14 \%)$ & $30(24 \%)$ \\
\hline $61-$ Above & $06(05 \%)$ & $10(08 \%)$ & $16(13 \%)$ \\
\hline Settlement & & & \\
\hline Rural & $33(27 \%)$ & $39(31 \%)$ & $72(58 \%)$ \\
\hline Urban & $24(19 \%)$ & $29(23 \%)$ & $53(42 \%)$ \\
\hline Occupation & & & \\
\hline Student & $17(13 \%)$ & $12(10 \%)$ & $29(23 \%)$ \\
\hline Civil servant & $12(10 \%)$ & $01(01 \%)$ & $13(11 \%)$ \\
\hline Farming & $14(11 \%)$ & $05(04 \%)$ & $19(15 \%)$ \\
\hline Trading & $08(06 \%)$ & $02(02 \%)$ & $10(08 \%)$ \\
\hline House wives & $00(00 \%)$ & $48(38 \%)$ & $48(38 \%)$ \\
\hline Others & $06(05 \%)$ & $00(00 \%)$ & $06(05 \%)$ \\
\hline
\end{tabular}

\section{Prevalence of Typhoid fever according to Diagnostic Methods}

The prevalence of typhoid fever based on the diagnostic method used in this study is presented in Table-2. The result showed that out of the 125 patients involved in the study, $22(17.6 \%)$ tested positive for Salmonella typhi by Widal test, whereas $17(13.6 \%)$ tested positive by stool culture.

Table-2: Prevalence of typhoid fever based on the diagnostic methods used

\begin{tabular}{|l|l|l|l|l|}
\hline Methods & No. of samples & No. of positive & No. of negative & P value \\
\hline Widal test & 125 & $22(17.6 \%)$ & $103(82.4 \%)$ & $.383482^{*}$ \\
\hline Stool culture & 125 & $17(13.6 \%)$ & $108(86.4 \%)$ & \\
\hline
\end{tabular}

Key: * Result not significant $(p<0.05)$

\section{Prevalence of Typhoid fever based on Sex and Age}

Table-3 represents the prevalence of typhoid fever based on gender and age category of the patients. The result showed that patients within the age category 21 - 40 years has the highest incidence of typhoid fever $9(7.2 \%)$ and 7 $(5.6 \%)$ for Widal test and stool culture respectively. On the basis of gender, despite they have less number of febrile 
patients, male has the highest prevalence of typhoid fever with 12 and 10 individuals $(9.6 \%$ and $8 \%)$ while 10 and 7 individual positive samples were female accounted for $8 \%$ and $5.6 \%$ for widal test and stool culture respectively.

Table-3: Prevalence of typhoid fever based on Sex and Age of the respondents

\begin{tabular}{|l|c|l|l|l|l|l|}
\hline & \multicolumn{3}{|c|}{ Widal test } & \multicolumn{3}{l|}{ Stool culture } \\
\hline Parameter & + & - & P value & + & - & P value \\
\hline Age (years) & & & & & & \\
\hline $0-20(\mathrm{n}=32)$ & 05 & 27 & $.903279^{*}$ & 03 & 29 & $.847159^{*}$ \\
\hline $21-40(\mathrm{n}=47)$ & 09 & 38 & & 07 & 40 & \\
\hline $41-60(\mathrm{n}=30)$ & 06 & 24 & & 05 & 25 & \\
\hline Above 61 (n=16) & 02 & 14 & & 02 & 14 & \\
\hline Sex & & & & & & \\
\hline Male $(\mathrm{n}=57)$ & 12 & 45 & $.3533385^{*}$ & 10 & 47 & $.238918^{*}$ \\
\hline Female $(\mathrm{n}=68)$ & 10 & 58 & & 07 & 61 & \\
\hline
\end{tabular}

Key: * Result not significant $(p<0.05)$

\section{Sensitivity and Specificity of Widal test against Stool culture}

The sensitivity, specificity, positive and negative predictive values of Widal test against stool culture is presented in Table 4. This means that since stool culture was considered the ideal to which Widal would be compared to, its sensitivity and specificity when cultured for S. typhi using the MacConkey and Salmonella Shigella agar were $100 \%$ each. Sensitivity is the probability that a truly infected individual will test positive, while specificity is the probability that a truly uninfected individual will test negative. Among 22 positive Widal tests, only 15 were positive for stool culture, and the two more positive stool cultures were negative with Widal test. Widal sensitivity was $78.9 \%$ while its specificity was $93.6 \%$ as compared to the ideal $100 \%$ sensitivity and specificity of stool culture. The Positive Predictive Value (PPV) and Negative Predictive Value (NPV) of Widal were 68.2\% and $98.1 \%$ respectively

Table-4: Sensitivity and Specificity of Widal test against Stool Culture

\begin{tabular}{|l|l|}
\hline Results & Widal test \\
\hline Sensitivity (\%) & 78.9 \\
\hline Specificity (\%) & 93.6 \\
\hline PPV (\%) & 68.2 \\
\hline NPV (\%) & 98.1 \\
\hline
\end{tabular}

Key: PPV = Positive predictive value, NPV = Negative predictive value

\section{DISCUSSION}

In developing countries like Nigeria, Widal test is the common serological test used to diagnose typhoid fever. The findings in the present study suggest a low prevalence of $17.6 \%$ and $13.6 \%$ among febrile patients using Widal test and stool microscopy respectively. This prevalence rate is lower than that of Wam et al., [18] in Cameroun who a prevalence of $39.3 \%$ in patients using the stool culture method and a prevalence of $57.1 \%$ using the Widal test method. The result is lower than that of Gemechu et al., [19], which showed a high prevalence of typhoid fever (20\%) using stool culture and $68.4 \%$ using Widal test method in Ethiopia. On the other hand, this result is lower than that of Verma et al., [20] in Northern India who found prevalence rate of $10.8 \%$ and 3.3\% for Widal test and stool culture respectively. Low prevalence rate of typhoid fever among febrile patients in this study is attributed to high malaria prevalence in the area.

There is high prevalence of typhoid fever from Widal test when compared to stool culture according to the present study. This finding was in conformity with the findings of Wam et al., [18]; Gemechu et al., [19] and Verma et al., [20]. The high Widal prevalence in the present study could be associated with cross-reacting antibodies from febrile patients other than typhoid fever [18]. According to the result of the present study, individuals of all age are susceptible to infection by $S$. typhi. The age group more susceptible to the present study was those between $21-40$ years old (However, the result is not significant $p<0.05$ ). This is in agreement with the studies conducted Wam et al., [18] and Ramyil et al., [21] who both found 21 - 30 and $24-29$ years were more susceptible to typhoid fever respectively. According to Wam et al., [18], this could be due to improper sanitation and hygiene. Both children and adults can get typhoid fever through ingestion of contaminated food and water. Travelling to high-risk destinations presents a high risk of contracting typhoid fever [22].

With respect to the gender of the febrile patients, males has the highest prevalence of typhoid fever with 12 and 10 individuals $(9.6 \%$ and $8 \%$ ) while 10 and 7 individual positive samples were female accounted for $8 \%$ and $5.6 \%$ for widal test and stool microcopy respectively. This finding also agrees with that of Ramyil et al., [21] which showed that the males were more positive to Widal test and stool culture than females. However, the result contradicts those of Wam 
et al., [18] and Gemechu et al., [19] who both found higher incidence of typhoid fever in female than male. High prevalence of typhoid fever among male in the study area is attributed to high involvement in outdoor activities by male than female in the study area, hence, they are more exposed to the infection.

The result of the present study demonstrated high sensitivity and specificity of Widal test as $78.9 \%$ and $93.6 \%$ respectively. This finding was in conformity with the finding of Gemechu et al., [19] high sensitivity of Widal test $(84.2 \%)$. This result contradicts that of Wam et al., [18] who recorded low sensitivity and specificity of Widal test when compared to stool culture as $40.9 \%$ and $32.4 \%$ respectively. The positive predictive value (PPV) and negative predictive value (NPV) of Widal test were high according to the present study, that is, $68.2 \%$ and $98.1 \%$ respectively. This means that most of the proportion of patients with positive test results that are correctly diagnosed. On the other hand, the NPV value of Widal test was $98.1 \%$. This indicates that a negative Widal test result has a good predictive value for the absence of the disease.

\section{Conclusion}

In the present study, there is low prevalence of typhoid fever among febrile patients in the study area. There is high prevalence of typhoid fever from Widal test (17.6\%) when compared to stool culture (13.6\%). According to the result, more male were infected than female. Based on the findings of this study, Widal test has high sensitivity, specificity, positive predictive value (PPV) and negative predictive value (NPV). Therefore, Widal test can be used as a diagnostic method for detection of Salmonella typhi. It is recommended that Widal test can still be used for the diagnosis of enteric fever

\section{ACKNOWLEDGEMENT}

The authors wish to acknowledge the Ministry of Health Kano State and Department of Health Kumbotso Local Government Area for their support and ethical approval. Thanks to technical staff of the Hospitals in the study area for their guidance, samples provision and use of Laboratory facilities.

Conflict of interest: The authors declare no conflict of interest exist.

\section{REFERENCES}

1. Bhanu, S., Vandana, S., \& Archana, S. (2001). Comparative study of the diagnostic procedures in salmonella infection, causative agent of typhoid fever - an overview study. IRJP. 2(9):127-129.

2. Andualem, G., Abebe, T., Kebede, N., Gebre-Selassie, S., Mihret, A., \& Alemayehu, H. A. (2014). Comparative study of Widal test with blood culture in the diagnosis of typhoid fever in febrile patients. BMC Res Notes. 7:653.

3. Coleman, W., \& Buxton, B. H. (1907). The bacteriology of the blood in typhoid fever. Am J Med Sci. 133:896-903.

4. Dheer, G., Kundra, S., \& Singh, T. (2012). Clinical and laboratory profile of enteric fever in children in northern India. Trop Doct. 42:154-6.

5. Gulati, S., \& Maheshwari, A. (2012). Dengue fever-like illnesses: How different are they from each other? Scand J Infect Dis. 44:522-530.

6. Prakash, P., Rajpal, K., \& Mahto, S. P. (2018). Comparative evaluation of diagnostic efficacy of widal slide agglutination test \& widal tube agglutination test in enteric fever. International Journal of Medical and Health Research. 4(10):181-183.

7. Encyclopedia Britannica. Fernand-Isidore Widal, Online, Web. 25 Apr. 2011; Updated on: 25 January 2008; Web Address: http://www.britannica.com/EBchecked/topic/643157/Fernand-Isidore-Widal; Accessed: 28 April 2008

8. Jenkins, C., \& Gillespie, S. H. (2009). Salmonella Infections. In: Gordon C. Cook Zumla AI. eds. Manson's Tropical Diseases, 22nd edition. China: Saunders Elsevier. 931-952.

9. Rodrigues, C. (2003). The Widal test more than 100 years old: abused but still used. Indian Journal Association of Physicians. 51:7-8.

10. Olopoenia, L. A., \& King, A. L. (2000). Widal agglutination test-100 years later: Still plagued by controversy. Postgraduate Journal of medicine. 76:80-84

11. Parry, C. M., Hoa, N. T. T., Diep, T. S., Wain, J., Chinh, N. T., Vinh, H., ... \& Farrar, J. J. (1999). Value of a singletube Widal test in diagnosis of typhoid fever in Vietnam. Journal of clinical microbiology, 37(9), 2882-2886.

12. Lewis, M. J. (1997). Salmonella, In: Medical Microbiology, Greenwood, D, Slack, R and Pebtherer, J, editors, 15th edition, ELST, USA, 252-261.

13. National Population Commission (NPC). (2006). National Population Census result, 2006 Abuja Nigeria.

14. Nas, F. S., Ali, M., \& Yahaya, A. (2018). Malaria and Typhoid Fever Co Kumbotso Local Government Area Kano, Nigeria. Bayero Journal of Pure and Applied Sciences, 10(2): 122-125.

15. Presscot, L. M., Harley, J. P., \& Klein, D. A. (2005) Microbiology 6th (Edn). McGraw Hill International edition New York. 
16. Chessbrough, M. (2006). District laboratory practice in tropical countries, second edition, part two, Cambridge university press. Examination of pus, ulcer material and skin specimens. 80-85.

17. Holt, J. G., Krieg, N. R., Senath, P. A., Staley, J. T., \& Williams, S. T. (1994). Bergey's Manual of Determinative Bacteriology 9th (Edn). Baltimore Md Williams and Wilkins.

18. Wam, E. C., Arrey, C. N., Sama, L. F., Agyingi, L. A., \& Wam, A. N. (2019). Comparative Study on the Use of Widal Test to Stool Culture in the Laboratory Diagnosis of Typhoid Fever in Holy Family Hospital Akum, North West Region of Cameroon. The Open Microbiology Journal, 13(1):73-80.

19. Ameya, G., Atalel, E., Kebede, B., \& Yohannes, B. (2017). Comparative study of Widal test against stool culture for typhoid fever suspected cases in southern Ethiopia. Pathology and Laboratory Medicine International, 9:1-7.

20. Verma, D., Kishore, S., \& Siddique, M. E. (2014). Comparative evaluation of various tests for diagnosis of concurrent malaria and typhoid fever in a tertiary care hospital of Northern India. Journal of Clinical and Diagnostic Research: JCDR, 8(5), DC41.

21. Ramyil, M. S., Ihuoma, O. J., Ogundeko, T. O., Ameh, J. M., Olorundare, F., Adeniyi, O. G., ... \& Izam, M. M. (2013). Comparative study on the use of Widal test and stool culture in the laboratory diagnosis of Salmonella infection in adult and children in Jos metropolis, Plateau State, Nigeria. Int J Sci Res, 2(12), 435-41.

22. Whitaker, J. A, Franco-Paredes, C., del Rio, C., \& Edupuganti, S. (2009). Rethinking typhoid fever vaccines: Implications for travelers and people living in highly endemic areas. J Travel Med. 16(1): 46-52. http://dx.doi.org/10.1111/j.1708-8305.2008.00273.x 